\title{
IMPLEMENTASI PENYUSUNAN INSTRUMEN EVALUASI YANG DIGUNAKAN OLEH WIDYAISWARA DALAM MENGUKUR KEBERHASILAN PELATIHAN DI BALAI BESAR PENDIDIKAN DAN PELATIHAN KESEJAHTERAAN SOSIAL LEMBANG
}

\author{
${ }^{1)}$ Lenny Nuraeni, ${ }^{2)}$ Dewi Safitri Elshap, ${ }^{3)}$ Prita Kartika \\ ${ }^{1)}$ lennynuraeni86@yahoo.com
}

Program Studi Pendidikan Guru PAUD, STKIP Siliwangi

\begin{abstract}
ABSTRAK
Masalah dalam penelitian ini yaitu, "Bagaimana prosedur penyusunan instrumen evaluasi pelatihan yang digunakan oleh widyaiswara untuk mengukur keberhasilan pelatihan di Balai Besar Pendidikan dan Pelatihan Kesejahteraan Sosial Lembang". Penelitian ini bertujuan untuk untuk memperoleh data dan informasi tentang prosedur penyusunan instrumen evaluasi pelatihan di Balai Besar Pendidikan dan Pelatihan Kesejahteraan Sosial Lembang, untuk memperoleh data dan informasi tentang prosedur pengujian instrumen evaluasi pelatihan di Balai Besar Pendidikan dan Pelatihan Kesejahteraan Sosial Lembang, serta untuk memperoleh data dan informasi pengolahan data hasil evaluasi pelatihan di Balai Besar Pendidikan dan Pelatihan Kesejahteraan Sosial Lembang. Landasan teoritis yang dibahas dalam penelitian ini adalah mengenai konsep pelatihan, konsep evaluasi dan pengertian instrumen evaluasi. Metode yang digunakan dalam kegiatan penelitian ini adalah metode deskriftif dengan teknik pengumpulan data adalah wawancara, observasi, studi dokumentasi dan studi literatur. Subjek utama penelitian ini adalah widyaiswara dan pengelola pelatihan di BBPPKS Lembang. Berdasarkan hasil temuan dari penelitian ini adalah sebagai berikut: 1) Prosedur penyusunan dan pengembangan instrumen tes yang dilakukan oleh widyaiswara di BBPPKS Lembangdimulai dari menetapkan tujuan tes, menetapkan hasil belajar yang akan diukur,mempersiapkan tabel spesifikasi (kisi-kisi), menetapkan isi materi tes, Menetapkan butir tes, menyiapkan norma aturan, dan mempersiapkan kunci skoring. 2) Prosedur pengujian instrumen evaluasi di BBPPKS Lembang tidak dilakukan pengujian validitas item soal dan pengujian reliabilitas instrumen evaluasi. Hal ini didasari alasan bahwa sifat pelatihan di BBPPKS Lembang yang dinamis sehingga tidak cukup waktu untuk melakukan pengujian tersebut, selain itu ada faktor kekurang pahaman beberapa widyaiswara menggunakan teknik statistik dalam pengujian tersebut.Tetapi secara keseluruhan instrumen evaluasi tersebut telah melewati langkah-langkah pengujian seperti validitas logis, validitas isi, validitas konstruk, validitas empiris, objektivitas, taraf kesukaran dan praktikabilitas. 3) Tahapan pengolahan data hasil evaluasi di BBPPKS Lembang Lembang dimulai dari pemeriksaan hasil evaluasi pembelajaran, perekapan data hasil evaluasi, pemberian skor, perubahan skor menjadi nilai dan analisis serta penafsiran data hasil evaluasi untuk pengambilan keputusan selanjutnya dilakukan secara berurutan sesuai dengan prosedur yang telah ditentukan oleh lembaga. Dari hasil analisis data yang dilakukan, maka dapat disimpulkan bahwa 1) Prosedur penyusunan dan pengembangan instrumen tes yang dilakukan oleh widyaiswara di BBPPKS Lembang telah sesuai dengan langkahlangkah penyusunan instrumen evaluasi pembelajaran yang baik. 2) Prosedur pengujian instrumen evaluasi di BBPPKS Lembang belum memenuhi kriteria ciri-ciri tes yang baik karena tidak dilakukan pengujian validitas item soal dan pengujian reliabilitas instrumen evaluasi. 3) Secara keseluruhan pengolahan data di Lembaga BBPPKS Lembang telah dilakukan dengan baik, tahapan pengolahan data hasil evaluasi yang dimulai dari pemeriksaan hasil evaluasi pembelajaran, perekapan data hasil evaluasi, pemberian skor, perubahan skor menjadi nilai dan analisis serta penafsiran data hasil evaluasi untuk pengambilan keputusan selanjutnya dilakukan secara berurutan sesuai dengan prosedur yang telah ditentukan oleh lembaga.
\end{abstract}

Kata Kunci: Implementasi Penyusunan Instrumen Evaluasi Pelatihan, BBPPKS Lembang 


\begin{abstract}
Problems in this study, namely, "How is the procedure of preparation of training evaluation instruments used by trainers to measure the success of the training at the Center for Education and Social Welfare Training Lembang". This study aimed to obtain data and information on procedures for the preparation of an evaluation instrument training at the Center for Education and Social Welfare Training Lembang, to obtain data and information on the testing procedures of evaluation instruments of training at the Center for Education and Social Welfare Training Lembang, as well as to obtain data and data processing information on the evaluation of training at the Center for Education and Social Welfare Training Lembang. Theoretical foundation discussed in this study is the concept of training, evaluation and understanding the concept of evaluation instruments. The method used in this research is descriptive method with data collecting technique is interview, observation, documentation studies and literature studies. The main subject of this study are trainers and training managers in BBPPKS Lembang. Based on the findings of this study are as follows: 1) The procedure for preparing and developing instrument tests conducted by trainers in BBPPKS Lembangdimulai of set purpose test, establish learning outcomes to be measured, prepare a table of specifications (lattice), specify the content of the test material, Establish test items, setting norms rules, and prepare the scoring key. 2) The testing procedure evaluation instrument in Lembang BBPPKS not done testing the validity and reliability testing item about evaluation instruments. It is based on the reason that the nature of the training in Lembang BBPPKS a dynamic that is not enough time to do such testing, there are factors besides lack of understanding some trainers use statistical techniques in testing tersebut.Tetapi overall evaluation instrument has passed the testing measures such as validity logical, content validity, construct validity, empirical validity, objectivity, the level of difficulty and praktikabilitas. 3) Stages of data processing evaluation results in BBPPKS Lembang Lembang start of the examination results of the evaluation of learning, perekapan evaluation data, scoring, score changes into value and the analysis and interpretation of evaluation data for decision making is then performed in sequence in accordance with the procedures specified by the institution. From the results of data analysis, it can be concluded that 1) the procedure for preparing and developing instrument tests conducted by trainers in BBPPKS Lembang in accordance with the steps the preparation of good learning evaluation instruments. 2) The testing procedure evaluation instrument in Lembang BBPPKS not meet the criteria of the characteristics of a good test because it is not a matter of testing the validity and reliability test item evaluation instruments. 3) Overall data processing at the Institute BBPPKS Lembang has done well, the stages of data processing results of the evaluation starts from the examination results of the evaluation of learning, perekapan evaluation data, scoring, score changes into value and the analysis and interpretation of evaluation data for decision making then performed sequentially in accordance with the procedures specified by the institution.
\end{abstract}

Keywords: Formulation Implementation Evaluation Instrument Training, BBPPKS Lembang

\section{A. PENDAhULUAN}

Pendidikan adalah usaha yang dilakukan oleh lembaga penyelenggara (instansi pemerintah, lembaga swadaya masyarakat, dan lain sebagainya) untuk mempersiapkan generasi yang lebih baik dimasa yang akan datang. Secara khusus pendidikan dilakukan oleh pelaksana pendidikan yaitu oleh, pendidik (guru, pamong belajar, tutor, pelatih, instruktur, widyaiswara) terhadap peserta para peserta didik supaya lebih mampu berperan dalam melaksanakan tugas, pekerjaan, dan kehidupan di masa depan. Dari pengertian itu pula dapat dipahami bahwa pelatihan merupakan bagian dari kegiatan pendidikan. Sedangkan kegiatan pengajaran, yang pada umumnya dilakukan pada pendidikan sekolah dengan pendekatan pedagogi, mempunyai hubungan dengan kegiatan pembelajaran yang lebih banyak diterapkan dalam pendidikan luar sekolah (pendidikan nonformal dan pendidikan informal) dengan menggunakan pendekatan andragogi.

Menurut undang-undang RI Nomor 20 Tahun 2003 Tentang Sistem Pendidikan Nasional, pasal 26 ayat (4) dinyatakan bahwa lembaga pelatihan merupakan satuan pendidikan nonformal, disamping satuan pendidikan lainnya yaitu, kursus, kelompok belajar, majelis ta'lim, kelompok bermain, TPA, Pusat Kegiatan Belajar Masyarakat, serta satuan pendidikan yang sejenis. Pelatihan dapat dilakukan dalam jenis dan ruang lingkup pendidikan nonformal. Ruang lingkup pendidikan nonformal adalah pendidikan anak usia dini, pendidikan keaksaraan, pendidikan kesetaraan, pendidikan kecakapan hidup, pendidikan 
kepemudaan, pendidikan pemberdayaan perempuan, pendidikan usia lanjut, dan pendidikan melalui media masa.

Pelatihan merupakan upaya pembelajaran, yang diselenggarakan oleh organisasi (instansi pemerintah, LSM, perusahaan, dan lain sebagainya) untuk memenuhi kebutuhan atau untuk mencapai tujuan organisasi. Suatu pelatihan dianggap berhasil apabila dapat membawa kenyataan atau performansi sumber daya manusia yang terlibat dalam organisasi pada saat ini kepada kenyataan atau performansi sumber daya manusia yang seharusnya atau yang diinginkan oleh organisasi atau lembaga. Adapun peran pelatih (widyaiswara, instruktur, nara sumber) dalam proses pembelajaran adalah membantu peserta pelatihan untuk dapat mengubah perilaku yang biasa ditampilkan pada saat ini menjadi perilaku yang seharusnya terwujud atau yang diharapkan oleh organisasi dan/atau lembaga. Definisi pelatihan menurut Center for Development Management and Productivity adalah belajar untuk mengubah tingkah laku orang dalam melaksanakan pekerjaan mereka.Pelatihan pada dasarnya adalah suatu proses memberikan bantuan bagi para karyawan atau pekerja untuk menguasai keterampilan khusus atau membantu untuk memperbaiki kekurangan dalam melaksanakan pekerjaan mereka.

Perbedaan yang nyata dengan pendidikan, diketahui bahwa pendidikan pada umumnya bersifat filosofis, teoritis, bersifat umum, dan memiliki rentangan waktu belajar yang relatif lama dibandingkan dengan suatu pelatihan. Sedangkan yang dimaksudkan dengan pembelajaran, mengandung makna adanya suatu proses belajar yang melekat terhadap diri seseorang. Pembelajaran terjadi karena adanya orang yang belajar dan sumber belajar yang tersedia.Dalam arti pembelajaran merupakan kondisi seseorang atau kelompok yang melakukan proses belajar.

Pelaku pembangunan kesejahteraan sosial dewasa ini dituntut untuk memiliki kompetensi dan daya kompetitif. Kompetensi dapat diartikan sebagai faktor mendasar yang dimiliki seseorang yang mempunyai kemampuan lebih, yang membuatnya berbeda dengan seorang yang mempunyai kemampuan rata-rata biasa saja. Sedangkan daya kompetitif sangat diperlukan ketika seseorang berhadapan dengan orang (pelaku) lain dalam memenangkan suatu keadaan atau peristiwa tertentu. Dengan dua kekuatan ini diharapkan dapat menghasilkan sumber daya manusia yang berkualitas dan mampu bersaing baik di tingkat regional maupun global.

Salah satu upaya untuk meningkatkan kompetensi dan daya kompetitif adalah melalui pendidikan dan pelatihan yang direncanakan, dilaksanakan, dievaluasi dan ditindak lanjuti secara terarah dan sistematis sehingga menjadikan satu kebutuhan dan keniscayaan untuk semua organisasi atau institusi pada era globalisasi dewasa.

Diklat akan efektif dan efisien apabila dilaksanakan dengan pendekatan integral. Pertama, menyangkut subjek/pelaku diklat dan kedua, terkait dengan proses/tahapan dalam penyelenggaraan diklat itu sendiri. Para pelaku pelaksana merupakan subjek yang harus secara aktif memberikan respon, peran, tanggung jawab dan akuntabilitas serta umpan balik yang harus dilaksanakan secara bersama baik oleh penyelenggara diklat, peserta diklat maupun oleh instansi pengirim peserta (atasan langsung peserta diklat). Selanjutnya, penyelenggara diklat harus memperhatikan manajemen diklat melalui tahapan perencanaan, pengorganisasian, pelaksanaan hingga pengevaluasian diklat yang terpadu dan berkelanjutan. Dengan kata lain, konsep dasar model pelatihan yang integral digambarkan bahwa diklat dimulai dengan proses penelusuran kebutuhan diklat, proses penentuan tujuan diklat, proses perencanaan program diklat, proses pelaksanaan diklat serta evaluasi diklat.

Balai Besar Pendidikan dan Pelatihan Kesejahteraan Sosial (BBPPKS) Lembang merupakan salah satu lembaga aparatur negara dari sekian banyak lembaga yang tersebar di Indonesia. BBPPKS bergerak dalam pengembangan kesejahteraan sosial yang dapat dikatakan merupakan salah satu jenjang pendidikan luar sekolah yang disediakan untuk masyarakat yang tersebar di seluruh Indonesia. Dengan adanya lembaga aparatur negara sangat membantu pemerintah dalam mengembangkan potensi dan pemenuhan kebutuhan masyarakat.

Dalam konteks pelaksanaan pendidikan dan pelatihan, evaluasi memegang peran yang penting, sehingga evaluasi tidak bisa diabaikan karena evaluasi dapat menilai apakah program itu berhasil, kurang berhasil, atau gagal. Sebab semakin jauh kita melangkah semakin banyak program kita canangkan, semakin perlu kita mempertanyakan seberapa efektif dan seberapa 
efisien program itu. Menguji merupakan bagian terpenting dalam pembelajaran, yang dilakukan oleh seorang pendidik untuk mengetahui tingkat pengetahuan awal, kecakapan siswa, dan program pengajaran. Ujian ini dapat dilakukan pada awal pelajaran untuk mengetahui sejauh mana tingkat pengetahuan awal siswa, dan uji akhir dari proses pembelajaran, yaitu untuk mendapat gambaran kecakapan, penyerapan dari suatu penyajian yang telah dilaksanakan pada akhir pelajaran. Evaluasi juga dapat menjadi acuan untuk memperbaiki kelemahan-kelemahan yang terjadi sebelumnya ataupun saat sedang berlangsungnya program pelatihan, sehingga kedepannya kegiatan pelatihan tersebut dapat berkembang dengan baik secara optimal sesuai dengan kebutuhan dan tujuan yang telah ditetapkan sebelumnya.

Evaluasi pembelajaran dalam pelatihan dapat dikatakan terlaksana dengan baik apabila instrumen evaluasi yang ada juga dipersiapkan dengan baik dan sesuai dengan acuan normatif. Sebuah instrumen evaluasi hasil belajar hendaknya memenuhi syarat sebelum di gunakan untuk mengevaluasi atau mengadakan penilaian agar terhindar dari kesalahan dan hasil yang tidak valid (tidak sesuai kenyataan sebenarnya).Instrumen pembelajaran berfungsi untuk membantu guru agar mudah dalam melaksanakan kegiatan penilaian. Keluasan dan kedalaman materi yang diuji dapat dituangkan secara komprehensif dalam sebuah instrumen, yang selanjutnya melalui instrumen itulah pelaksanaan tes dapat dilakukan. Oleh karena itu, guru perlu memahami esensi instrumen penilaian agar dalam pelaksanaan penilaian pembelajaran sesuai dengan yang diharapkan. Seringkali instrumen pembelajaran disusun secara asal-asalan sehingga menghasilkan instrumen yang kurang memenuhi kriteria instrumen yang baik untuk kegiatan penilaian pembelajaran. Alat evaluasi yang kurang baik dapat mengakibatkan hasil penilaian menjadi bias atau tidak sesuainya hasil penilaian dengan kenyataan yang sebenarnya, seperti contoh anak yang pintar dinilai tidak mampu atau sebaliknya.Jika terjadi demikian perlu ditanyakan apakah persyaratan instrumen yang digunakan menilai sudah sesuai dengan kaidahkaidah penyusunan instrumen. Setidak-tidaknya ada empat ciri atau karakteristik yang harus dimiliki oleh instrumen/alat evaluasi, sehingga instrumen tersebut dapat dinyatakan sebagai instrumen yang baik, yaitu valid, realibel, obyektif dan praktis.

Suatu instrumen evaluasi dikatakan baik apabila mampu mengevaluasi sesuatu yang dievaluasi dengan hasil seperti keadaan yang dievaluasi. Dalam menggunakan alat tersebut evaluator menggunakan cara atau teknik. Dan oleh karena itu dikenal dengan teknik evaluasi. Seperti disebutkan diatas, ada dua teknik evaluasi, yaitu teknik tes dan teknik nontes.Instrumen memegang peranan yang sangat penting dalam menentukan mutu suatu pelatihan, karena validitas atau kesahihan data yang diperoleh akan sangat ditentukan oleh kualitas atau validitas instrumen yang digunakan, di samping prosedur pengumpulan data yang ditempuh. Hal ini mudah dipahami karena instrumen berfungsi mengungkapkan fakta menjadi data, sehingga jika instrumen yang digunakan mempunyai kualitas yang memadai dalam arti valid dan reliabel maka data yang diperoleh akan sesuai dengan fakta atau keadaan sesungguhnya di lapangan. Sedangkan jika kualitas instrumen yang digunakan tidak baik dalam arti mempunyai validitas dan reliabilitas yang rendah, maka data yang diperoleh juga tidak valid atau tidak sesuai dengan fakta di lapangan, sehingga dapat menghasilkan kesimpulan yang keliru.

Keberhasilan suatu program pelatihan di mungkinkan apabila adanya keterlibatan masyarakat atau lembaga. Juga tidak kalah pentingnya adalah pelibatan para pelaksana/pengelola program secara tepat dalam proses evaluasi, sehingga memungkinkan hasil evaluasi dapat dimanfaatkan untuk perbaikan atau tindak lanjut program. Dalam hal ini instrumen evaluasi pada suatu pelatihan akan mempunyai peranan yang signifikan dalam memberikan arah dan masukan bagi para instruktur dan widyaiswara dalam mengukur keberhasilan pelatihan. Sehingga hasil dari pelaksanaan evaluasi dapat membantu bagi pengelola untuk memperoleh gambaran kegiatan pogram sesuai dengan tujuan yang telah ditetapkan.

Atas dasar pemikiran tersebut di atas penulis mencoba mengkaji dan meneliti secara lebih mendalam mengenai“"Prosedur Penyusunan Instrumen Evaluasi Pelatihan yang Digunakan oleh Widyaiswara untuk Mengukur Keberhasilan Pelatihan di Balai Besar Pendidikan dan Pelatihan Kesejahteraan Sosial (BBPPKS) Bandung.

Adapun yang menjadi penelitian ini yaitu antara lain:

1. Untuk memperoleh data dan informasi tentang prosedur penyusunan instrumen evaluasi 
pelatihan di Balai Besar Pendidikan dan Pelatihan Kesejahteraan Sosial.

2. Untuk memperoleh data dan informasi tentang prosedur pengujian instrumen evaluasi pelatihan di Balai Besar Pendidikan dan Pelatihan Kesejahteraan Sosial

3. Untuk memperoleh data dan informasi pengolahan data hasil evaluasi pelatihan di Balai Besar Pendidikan dan Pelatihan Kesejahteraan Sosial.

Dari penelitian ini diharapkan dapat memberikan manfaat sebagai berikut :

a. Manfaat Teoritis

Menambah pengetahuan dan referensi bagi penulis mengenai pengelolaan program khususnya dalam penyusunan instrumen evaluasi pelatihan serta dapat memberikan pengetahuan terhadap konsep-konsep ilmu pengetahuan, khususnya konsep pendidikan luar sekolah.

b. Manfaat Praktis

Dapat memberikan saran dan masukan perbaikan bagi peningkatan kualitas penyelenggaraan program pelatihan

\section{B. KAJIAN TEORI DAN METODE}

\section{Kajian Teori}

\section{a. Konsep Pelatihan}

Pelatihan secara singkat didefinisikan sebagai suatu kegiatan untuk meningkatkan kinerja saat ini dan kinerja di masa mendatang. Pelatihan adalah proses secara sistematis mengubah tingkah laku pegawai untuk mencapai tujuan organisasi. Pelatihan berkaitan dengan keahlian dan kemampuan pegawai untuk melaksanakan pekerjaan saat ini.Pelatihan memiliki orientasi saat ini dan membantu pegawai untuk mencapai keahlian dan kemampuan tertentu agar berhasil dalam melaksakan pekerjaannya. Menurut Kenneth R. Robinson (1998) dalam Soebagio Atmodiwiro, (2002: 37) pendidikan dan pelatihan adalah proses kegiatan pembelajaran antara pengalaman untuk mengembangkan pola perilaku seseorang dalam bidang pengetahuan, keterampilan atau sikap untuk mencapai standar yang diharapkan

\section{b. Konsep Evaluasi}

Evaluasi yang pada awalnya dikaitkan dengan prestasi belajar, kini memiliki pengertian yang lebih luas. Tyler (1950) dalam Djuju Sudjana
(2007: 210) mengemukakan bahwa evaluasi adalah proses pengumpulan data untuk mengetahui tentang sejauhmana, hal apa, dan bagian mana dari tujuan pelatihan itu tercapai. Croncbach dann Stufflebeam menambahkan bahwa evaluasi bukan hanya mengukur sejauhmana tujuan telah tercapai tetapi digunakan pula untuk pengambilan keputusan. Secara fisolofis, Rothwell (1996) memberi arti bahwa evaluasi adalah proses menentukan nilai (value). Nilai disini menunjukan derajat sesuatu yang dievaluasi dengan kategori baik atau buruk, penting atau tidak penting, bermanfaat atau tidak bermanfaat, tinggi atau rendah, berhasil atau tidak berhasil, dan lain sebagainya. Nilai dapat mencerminkan sejauhmana tingkatan keterampilan, pengetahuan, sikap dan atau nilai-nilai yang diperoleh peserta pelatihan selama dan atau setelah mengikuti proses pelatihan.

\section{c. Konsep Instrumen Evaluasi}

Pengertian instrumen dalam lingkup evaluasi didefinisikan sebagai perangkat untuk mengukur hasil belajar peserta didik yang mencakup hasil belajar dalam ranah kognitif, afektif, dan psikomotor.Bentuk instrumen dapat berupa tes dan non-tes. Instrumen bentuk tes mencakup: tes uraian (uraian objektif dan uraian bebas), tes pilihan ganda, jawaban singkat, menjodohkan, benar salah, unjuk kerja (performance test), dan portofolio. Instrumen bentuk non-tes mencakup: wawancara, angket, dan pengamatan (observasi).Sebelum instrumen digunakan hendaknya dianalisis terlebih dahulu.Dua karakteristik penting dalam menganalisis instrumen adalah validitas dan reliabilitasnya.Instrumen dikatakan valid (tepat, absah) apabila instrumen digunakan untuk mengukur apa yangseharusnya diukur. Instrumen untuk mengukur kemampuan matematika siswasekolah dasar tidak tepat jika digunakan pada siswa sekolah menengah.Dalamhal ini sasaran kepada siapa instrumen itu ditujukan merupakan salah satu aspekyang harus dipertimbangkan dalam menganalisis validitas suatu instrumen.

\section{Metode}

Metodologi yang digunakan penulis dalam penelitian ini adalah metode deskriptif dengan pendekatan kualitatif. Metode deskriptif merupakan cara penelitian dengan menggambarkan peristiwa yang ada pada masa sekarang atau yang sedang terjadi. Sebagaimana pendapat Nawawi (1983) : 
"Penelitian deskriptif adalah usaha mengungkapkan suatu masalah atau keadaan atau peristiwa sebagaimana adanya sehingga bersifat sekedar untuk mengungkapkan fakta (fact finding). Hasil penelitian ditekan pada memberikan gambaran secara objektif tentang keadaan sebenarnya dari objek yang diselidiki”.

Alasan penulis menggunakan metode deskriptif ini adalah karena metode ini merupakan metode yang dirasa paling cocok untuk diterapkan dan digunakan dalam penelitian yang penulis ambil, karena mengungkap permasalahan yang ada kaitannya dengan situasi dan kondisi saat ini.

Winarno Surakhmad (1990: 140) mengemukakan ciri-ciri metode deskriptif sebagai berikut :

a. Memusatkan diri pada pemecahan masalahn yang ada pada masa sekarang, yang sifatnya aktual.

b. Data yang aktual dikumpulkan, disusun, dijelaskan, dan dianalisis sehingga metode ini disebut juga metode analitik.

Dengan demikian, dapat disimpulkan bahwa tujuan penelitian ini adalah untuk menggambarkan dan mencoba mempelajari suatu keadaan atau kondisi kegiatan, yaitu prosedur penyusunan instument evaluasi pelatihan yang digunakan oleh widyaiswara untuk mengukur keberhasilan pelatihan di Balai Besar Pendidikan dan Pelatihan Kesejahteraan Sosial (BBPPKS) yang terjadi di masa sekarang dan manfaatnya tidak hanya dapat dirasakan sekarang tetapi dapat menjadi suatu bahan evaluasi atau perbaikan untuk masa yang akan datang.

\section{HASIL DAN PEMBAHASAN}

\section{Hasil}

\section{a. Gambaran Umum Lokasi Penelitian}

Sebagai unit pelaksanaan kediklatan Departemen Sosial yang memiliki tugas untuk menempa dan membentuk sumber daya manusia yang berkualitas dibidang kesejahteraan sosial. Unit pelaksanaan teknis ini diawali pada tahun 1964 di Yogyakarta dengan nama Balai Pendidikan Tenaga Sosial (BPTS), pada tahun 1974 pindah ke bandung berganti nama dengan National Training Course (NTC) dan pda tahun 1975 terjadi perubahan nomenklatur menjadi Balai Pendidikan dan Tenaga Sosial (BPTS) selanjutnya pada tahun 1996 berganti nama menjadi Balai Diklat Profesi Pekerjaan Sosial (BDPPS).

Pada tahun 2000 sampai sekarang sesuai dengan kepmensos nomor: 53/HUK/2003 tanggal 23 Juli 2003 bernama Balai Besar Pendidikan dan Pelatihan Kesejahteraan Sosial (BBPPKS) Bandung. Balai Besar Pendidikan dan Pelatihan Kesejahteraan Sosial (BBPPKS) Bandung ini, mencakup enam wilayah kerja, yaitu:

1) Kepulauan Bangka Belitung

2) Lampung

3) Banten

4) DKI Jakarta

5) Jawa Barat

6) Kalimantan Barat

Balai Besar Pendidikan dan Pelatihan Kesejahteraan Sosial juga menjalin kemitraan dengan:

a) Perguruan tinggi

b) Pemerintah daerah khususnya di wilayah kerja BBPPKS Bandung

c) Badan/Lembaga Diklat Non Pemerintah

d) Lembaga Lainnya

\section{Pembahasan}

\section{a. Prosedur Penyusunan Instrumen Evaluasi Pelatihan di Balai Besar Pendidikan dan Pelatihan Kesejahteraan Sosial (BBPPKS) Lembang.}

Dari hasil penelitian diperoleh gambaran bahwa dalam penyusunan dan pengembangan instrumen evaluasi, widyaiswara di BBPPKS Lembang selalu menyesuaikan dengan tujuan pembelajaran, materi latihan dan juga tujuan dari pelatihan yang diselenggarakan. Hal ini dilakukan untuk mengukur tingkat pencapaian dari peserta pelatihan yang dari hasil evaluasinya akan dijadikan dasar bagi widyaiswara dalam memperbaiki proses pembelajaran. Para widyaiswara beranggapan bahwan instrumen yang baik akan mendukung kegiatan penilaian dalam proses pelatihan, apakah telah tercapai sesuai dengan tujuan pelatihan dan juga tujuan pembelajaran dalam pelatihan.

\section{b. Prosedur Pengujian Instrumen Evaluasi Pelatihan di Balai Besar Pendidikan dan Pelatihan Kesejahteraan Sosial (BBPPKS) Lembang}


Berdasarkan hasil penelitian diperoleh gambaran secara umum bahwa instrumen evaluasi yang telah disusun oleh widyaiswara di BBPPKS Lembang tidak diuji validitasnya dengan menggunakan teknik statistik.Tapi untuk validitas logis, validitas empirik, validitas isi dan validitas konstruksi dari instrumen evaluasi hasil belajar dilakukan pengujian oleh widyaiswara. Penganalisisan terhadap tes hasil belajar sebagai suatu totalitas dapat dilakukan dengan dua cara. Pertama, penganalisisan terhadap jalan berpikir secara rasional atau penganalisisan dengan menggunakan logika.Kedua, penganalisisan yang dilakukan dengan mendasarkan diri kepada kenyataan empiris.Dari hasil penelitian dapat diperoleh informasi bahwa widyaiswara di BBPPKS Lembang selalu melakukan pengujian validitas secara rasional/logis termasuk pengujian terhadap validitas isi dan validitas konstruksi.Widyaiswara selalu menguji validitas rasional dengan menganalisis apakah instrumen tersebut sudah dirancang dengan baik, apakah telah sesuai dengan materi yang telah diajarkan atau belum. Sedangkan dari segi isi tes, widyaiswara di BBPPKS melakukan pengujian dengan mengkaji setiap butir soal apakah sudah mewakili dari isi materi yang telah diberikan kepada peserta pelatihan.

\section{c. Pengolahan Data Hasil Evaluasi Pelatihan di Balai Besar Pendidikan dan Pelatihan Kesejahteraan Sosial (BBPPKS)}

Berdasarkan hasil penelitian dapat diperoleh gambaran secara umum bahwa tujuan pengolahan data hasil evaluasi di Balai Besar Pendidikan dan Pelatihan Kesejahteraan Sosial (BBPPKS) Lembang adalah untuk mengubah data mentah sebagai hasil dari evaluasi pembelajaran menjadi data halus dan bermakna berupa nilai sehingga memudahkan untuk menganalisisnya. Hasil pengolahan data juga berguna bagi widyaiswara untuk mengukur keberhasilan mereka dalam menyampaikan materi kepada peserta pelatihan.Hal ini sesuai dengan yang dikemukakan oleh Djuju Sudjana (2007:225) bahwa tujuan pengolahan data adalah untuk mengubah data mentah sebagai hasil pengukuran menjadi data lebih halus dan bermakna sehingga memudahkan untuk pengkajian lebih lanjut. Kegiatan pengolahan data dilakukan melalui: (a) memeriksa hasil tes dengan menggunakan kunci jawaban dan memberi distribusu frekuensi skor untuk tes dan frekuensi jawaban untuk angket yang menghasilkan data nominal dan (c) mengkaji tabel distribusi sesuai dengan kebutuhan penilaian dan jenis data yang diperoleh. Melalui ketiga kegiatan ini diharapkan dapat diperoleh besaran aspekaspek yang dinilai

\section{KESIMPULAN}

Berdasarkan dari hasil penelitian yang telah diolah dan dianalisis pada BAB IV, dapat disimpulkan sebagai berikut:

1. Prosedur penyusunan instrumen evaluasi pelatihan di Balai Besar Pendidikan dan Pelatihan Kesejahteraan Sosial (BBPPKS) Lembang.

Prosedur penyusunan dan pengembangan instrumen tes yang dilakukan oleh widyaiswara di Balai Besar Pendidikan dan Pelatihan Kesejahteraan Sosial (BBPPKS) telah sesuai dengan langkah-langkah penyusunan instrumen evaluasi pembelajaran yang baik dimulai dari 1) menetapkan tujuan tes, 2) menetapkan hasil belajar yang akan diukur, 3) mempersiapkan tabel spesifikas (kisi-kisi), 4) Menetapkan isi materi tes, 5) Menetapkan butir tes, 6) menyiapkan norma aturan, dan 7) mempersiapkan kunci scoring. Melihat kenyataan tersebut dapat dikatakan bahwa prosedur penyususnan instrumen evaluasi pelatihan bentuk tes di Balai Besar Pendidikan dan Pelatihan Kesejahteraan Sosial (BBPPKS) Lembang telah sesuai dengan kaidah-kaidah penyusunan instrumen evaluasi. Sedangkan untuk instrumen bentuk non tes, prosedur penyusunan instrumennya belum sesuai dengan langkah-langkah penyusunan instrumen bentuk non tes yang baik yaitu dimulai dari: 1). Pengembangan spesifikasi alat ukur; 2). Penulisan pernyataan atau pertanyaan; 3). Penelaahan pernyataan atau pertanyaan; 4). Perakitan instrumen (untuk keperluan uji-coba); 5). Uji-coba; 6).Analisis hasil uji-coba; 7).Seleksi dan perakitan instrumen; 8).Administrasi instrumen; 9). Penyusunan skala dan norma. Dikatakan belum sesuai karena tidak dilakukan uji coba pada instrumen evaluasi non tes yang telah disusun.

2. Prosedur pengujian instrumen evaluasi pelatihan di Balai Besar Pendidikan dan Pelatihan Kesejahteraan Sosial (BBPPKS) Lembang

Prosedur pengujian instrumen evaluasi di Balai Besar Pendidikan dan Pelatihan Kesejahteraan Sosial (BBPPKS) Lembang belum memenuhi kriteria ciri-ciri tes yang baik karena tidak dilakukan pengujian validitas item soal dan 
pengujian reliabilitas instrumen evaluasi. Hal ini tidak sesuai dengan ciri-ciri tes yang baik apabila yang dibuat adalah tes standar, karena bahwa untuk menyusun tes standar dibutuhkan waktu yang lama, seperti yang disebutkan bahwa untuk memperoleh sebuah tes standar harus melalui prosedur: penyusunan, uji coba, analisis, revisi dan edit. Tetapi jika tes tersebut buatan widyaiswara yang digunakan untuk menentukan seberapa baik peserta latih/peserta didik menguasai bahan pelajaran yang diberikan dalam waktu tertentu maka secara keseluruhan instrumen tersebut bisa dikatakan cukup baik karena melewati langkahlangkah pengujian seperti validitas logis, validitas isi, validitas konstruk, validitas empiris, objektivitas, taraf kesukaran dan praktikabilitas. Dapat disimpulkan cukup baik karena untuk tes buatan widyaiswara yang paling penting adalah kelogisan, kesesuaian dengan materi, dan kesesuaian dengan tujuan instruksional yang ingin dicapai, hal tersebut hanya diketahui oleh widyaiswara itu sendiri yang bertanggung jawab pada suatu pelatihan dan sesuai dengan apa yang ingin dicapai oleh widyaiswara setelah proses pembelajaran.

\section{Pengolahan data hasil evaluasi pelatihan di Balai Besar Pendidikan dan Pelatihan Kesejahteraan Sosial (BBPPKS) Lembang}

Pengolahan data hasil evaluasi di BBPPKS Lembang sepenuhnya dilaksanakan oleh pihak penyelenggara khususnya bidang evaluasi.Tujuan pengolahan data hasil evaluasi di Balai Besar Pendidikan dan Pelatihan Kesejahteraan Sosial (BBPPKS) Lembang adalah untuk mengubah data mentah sebagai hasil dari evaluasi pembelajaran menjadi data halus dan bermakna berupa nilai sehingga memudahkan untuk menganalisisnya. Hasil pengolahan data juga berguna bagi widyaiswara untuk mengukur keberhasilan mereka dalam menyampaikan materi kepada peserta pelatihan.Secara keseluruhan pengolahan data di Lembaga BBPPKS Lembang telah dilakukan dengan baik, tahapan pengolahan data hasil evaluasi yang dimulai dari pemeriksaan hasil evaluasi pembelajaran, perekapan data hasil evaluasi, pemberian skor, perubahan skor menjadi nilai dan analisis serta penafsiran data hasil evaluasi untuk pengambilan keputusan selanjutnya dilakukan secara berurutan sesuai dengan prosedur yang telah ditentukan oleh lembaga.

\section{E. DAFTAR PUSTAKA}

Atmodiwiro, Soebagio. 2002. Manajemen Pelatihan. Jakarta: PT Ardadizya Jaya.

Arikunto, S. (2006). Manajemen penelitian. Jakarta: Rineka Cipta

Arikunto, S. (2009). Evaluasi Program Pendikdikan. Jakarta: PT Bumi Aksara

Daryanto. (2008). Evaluasi Pendidikan. Jakarta: PT Rineka Cipta

Depdiknas. (2003). Undang-undang RI No. 20 Tahun 2003 tentang sistem pendidikan nasional. Bandung

Hamalik, Oemar. (2007). Manajemen pelatihan ketenagakerjaanpendekatan terpadu: pengembangan sumber daya manusia. Jakarta: PT Bumi Aksara

Malyasari, Henny. (2005). Pelaksanaan Monitoring dan Evaluasi Hasil Pelatihan Prosesing oleh BLKP Lembang di Desa Munjul Kabupaten Cianjur. Skripsi UPI: Tidak diterbitkan

Sudijono, Anas. (2011). Pengantar Evaluasi Pendidikan. Jakarta: PT Raja Grafindo

Sudjana, D. (2001). Pendidikan Luar Sekolah (Wawasan Sejarah Perkembangan Falsafah Teori Pendukung Asas). Bandung: Falah Production. (2004). Manajemen Program Pendidikan untuk Pendidikan Nonformal dan Pengembangan Sumber Daya Manusia. Bandung: Falah Production.

--ovaluasi Program Pendidikan Luar Sekolah. Bandung: Rosda.

------. (2007). Sistem dan Manajemen Pelatihan Teori dan Aplikasi. Bandung: Falah Production

Sugiyono. (2009). Metode Penelitian Pendidikan Pendekatan Kuantitatif, Kualitatif, dan $R \& D$. Bandung: Alfabeta

Phillips, J Jack. (1991). Handbook of Training Evaluation and Measurement Methods. Texas: Gulf Publishing Company

Lawson, Karen. (2006). The Trainers Handbook: Preiffer.

Dina. (2010). http://www.slideshare.net/ sd4purwodadi/instrumen-penilaianpem belajaran. [20 Agustus 2011]

Endang Swastyaskuningsih. (2009). http://stahdnj. ac.id/?p=67. Kriteria Instrumen Evaluasi Harus Memenuhi Syarat Sebelum di gunakan. [15 September 2011] 
Fatimah. (2010). Evaluasi Program Pelatihan. [Online]. Tersedia:

http://www.umpwr.ac.id/web/download/pu blikasiilmiah/EvaluasiProgramPelatihan.p $d f$. [ 1 Agustus 2011]

Kodir, Ibnu. (2010). Definisi dan arti pentingnya kualitas. [Online]. Tersedia: http://www.ilmumanajemen.com/index.php ?option $=$ com_content \&view $=$ article $\& i d=$ 70: def\&catid=38: mnkua\&Itemid $=29 .[25$ Juli 2011]

Anonim. (2010). Definisi Kisi-kisi instrumen. [online]. Tersedia: http://jurnalsdm.blogspot.com/2009/09/sistemmanajemen-kualitas-qms-definisi.html. [25 Juli 2011]

Intermedia. (2010). Definisi pelatihan SDM. [Online]. Tersedia: http://isjd.pdii.lipi.go.id/admin/jurnal/1040 7371379. [ 28 Juli 2011]

Rina. (2009). http://www.scribd.com/doc/7529555 Training-Evaluation-Model. [5 September 2011]

Rika Sa'diyah. (2010). http://www.fai.umj.ac.id/index.php?option =com. [8 Agustus 2011]

Rouli, Lamria. (2009). Pendidikan dan Pelatihan. [Online]. Tersedia: http://stahdnj.ac $. i d / ? p=67$. [1 Agustus 2011]

Romli. (2010). http://www.deptan.go.id /bpsdmp/admin/download/ppt_tanpan.pdf. [13 September 2011]

Sasongko, Djoko. (2008). Prosedur Penilaian. [Online]. Tersedia: http://djokosasongko.blogspot.com/2008/12/definisikualitas.html. [ 25 juli 2011]

Sitimasrurohum. http://sitimasrurohum.blogspot.com/2009/ 05/desain-robot.html. evaluasi pembela jaran, [5 Agustus 2011]

Yanti. (2009). http://lpp.uns.ac.id/wp-content/ media/PANDUAN-EVALUASI-PEMBE LAJARAN.pdf. [10 agustus 2011]. 